EPJ Web of Conferences 41, 03005 (2013)

DOI: $10.1051 /$ epjconf/20134103005

(C) Owned by the authors, published by EDP Sciences, 2013

\title{
Ultrafast Hot Electron Induced Phase Transitions in Vanadium Dioxide
}

\author{
M. Hada ${ }^{1}$, Y. Hontani ${ }^{2}$, R. E. Marvel ${ }^{3}$, R. F. Haglund Jr. ${ }^{3}$, J. Matsuo ${ }^{2}$ \\ ${ }^{1}$ Max Planck Research Department for Structural Dynamics, Center for Free Electron Laser Science, \\ University of Hamburg, c/o DESY, Notkestrasse 85, Hamburg, 22607, Germany \\ ${ }^{2}$ Quantum Science and Engineering Center, Kyoto University, Gokasho, Uji, Kyoto 611-0011, Japan \\ ${ }^{3}$ Department of Physics and Astronomy, Vanderbilt University, Nashville TN 37235-1807 USA
}

\begin{abstract}
The $\mathrm{Au} / \mathrm{Cr} / \mathrm{VO}_{2} / \mathrm{Si}$ system was investigated in pump-probe experiments. Hot-electrons generated in the $\mathrm{Au}$ were found to penetrate into the underlying $\mathrm{VO}_{2}$ and couple with its lattice inducing a semiconductor-to-metal phase transition in $\sim 2$ picoseconds.
\end{abstract}

\section{Introduction}

The semiconductor-to-metal transition (SMT) in vanadium dioxide $\left(\mathrm{VO}_{2}\right)$ is a canonical example of strongly correlated systems[1]. The first order SMT occurs at a Tc of $\sim 340 \mathrm{~K}$ and has been discussed as the basis for potential applications ranging from photoactive filters to ultrafast optical switching. The SMT in $\mathrm{VO}_{2}$ manifested by large changes in resistivity and optical properties[2,3] accompanied by a simultaneous structural changes[4,5] from the low-temperature monoclinic with band gap of $\sim 0.7 \mathrm{eV}[6]$ to high temperature rutile phase. It is generally agreed that SMT arises from the combination of Peierls and Mott mechanisms. It was recently reported that in $\mathrm{VO}_{2}$, the SMT can be assisted by scattering due to the surface plasmon resonance in a nanocomposite comprising an array of $\mathrm{Au}$ nanoparticles covered by a thin film of $\mathrm{VO}_{2}$ [7]. Here, we report that for an Au layer on top of $\mathrm{VO}_{2}$, it is possible with femtosecond pulses at proper wavelengths to directly dope the hot electrons from $\mathrm{Au}$ into $\mathrm{VO}_{2}$ layer and to observe the SMT phenomena without direct excitation of $\mathrm{VO}_{2}$, this approach provides a new means for inducing structural transitions - especially important along the ground state surface.

\section{Sample Preparation and experimental setup}

A polycrystalline $125 \mathrm{~nm}$-thick $\mathrm{VO}_{2}$ layer was grown on a $\mathrm{Si}(100)$ substrate by electron beam deposition, and the $\mathrm{VO}_{2}$ films were coated with $\mathrm{Cr}$ (1 nm thickness) and $\mathrm{Au}$ (20 nm thickness) films by thermal deposition. Switching behavior was verified by measuring the white light (tungsten filament) reflection intensity using an InGaAs photodetector while the sample temperature cycled from $25{ }^{\circ} \mathrm{C}$ to $100{ }^{\circ} \mathrm{C}$. Normal switching temperature, contrast and hysteresis were observed. The $\mathrm{Au} / \mathrm{Cr} / \mathrm{VO}_{2} / \mathrm{Si}$ samples were characterized by optical pump-probe experiments in reflection mode with a femtosecond regenerative laser amplifier. The 800-nm optical pump was focused on the sample at an incident angle of $4.3^{\circ}$ from the surface normal, while a $400-\mathrm{nm}$ p-polarized probe pulse

This is an Open Access article distributed under the terms of the Creative Commons Attribution License 2.0, which permits unrestricted use, distribution, and reproduction in any medium, provided the original work is properly cited. 


\section{EPJ Web of Conferences}

was focused on the pump spot at an incident angle of $60^{\circ}$ from the surface normal. The reflectivity from the samples was detected using standard lock-in methods.

\section{Results and Discussion}

The (1/e) penetration depth of the $800-\mathrm{nm}$ light in $\mathrm{VO}_{2}$ is $\sim 150 \mathrm{~nm}$, while penetration depth of the 400 -nm probe in $\mathrm{VO}_{2}$ is $\sim 30 \mathrm{~nm}$, which means that the probing area was uniformly excited by the optical pump pulses for the $\mathrm{VO}_{2} / \mathrm{Si}$ sample. However, the penetration depth of 800 -nm light in Au is $13 \mathrm{~nm}$ and the fluence reaching the $\mathrm{VO}_{2}$ film would be lower than the critical threshold needed to induce the phase transition. Figure 1 shows the changes in reflectivity as a function of delay time for $\mathrm{Au} / \mathrm{Cr} / \mathrm{VO}_{2} / \mathrm{Si}$ and $\mathrm{Au} / \mathrm{Cr} / \mathrm{Si}$. Below the threshold absorbed fluence of $2.8 \mathrm{~mJ} / \mathrm{cm}^{2}$, there was a shortterm decrease in reflectivity of the $\mathrm{Au} / \mathrm{Cr} / \mathrm{VO}_{2} / \mathrm{Si}$ film (Fig. 1a) $(\tau: 0.8 \mathrm{ps}$, it recovered in $\sim 5 \mathrm{ps}$ ), which was also observed for the $\mathrm{Au} / \mathrm{Cr} / \mathrm{Si}$ film (Fig. 1b), where $\tau$ is the characteristic time constant. This change was attributed to the hot electrons excitation or electron temperature changes in the gold layer[8]. Above the threshold fluence $\left(>3.0 \mathrm{~mJ} / \mathrm{cm}^{2}\right)$, a decrease in the relative contribution from the short-time component and appearance of longlived term reduction in the reflectivity were observed for the $\mathrm{Au} / \mathrm{Cr} / \mathrm{VO}_{2} / \mathrm{Si}$ film. The subtraction of the time-resolved reflectivity of $\mathrm{Au} / \mathrm{Cr} / \mathrm{Si}$ film from $\mathrm{Au} / \mathrm{Cr} / \mathrm{VO}_{2} / \mathrm{Si}$ film with same laser absorbed fluence shows the time-scale of this phase transition phenomena in $\mathrm{Au} / \mathrm{Cr} / \mathrm{VO}_{2} / \mathrm{Si}$ film (Fig. 1c); this phase transition occurred within about $\sim 2 \mathrm{ps}$.
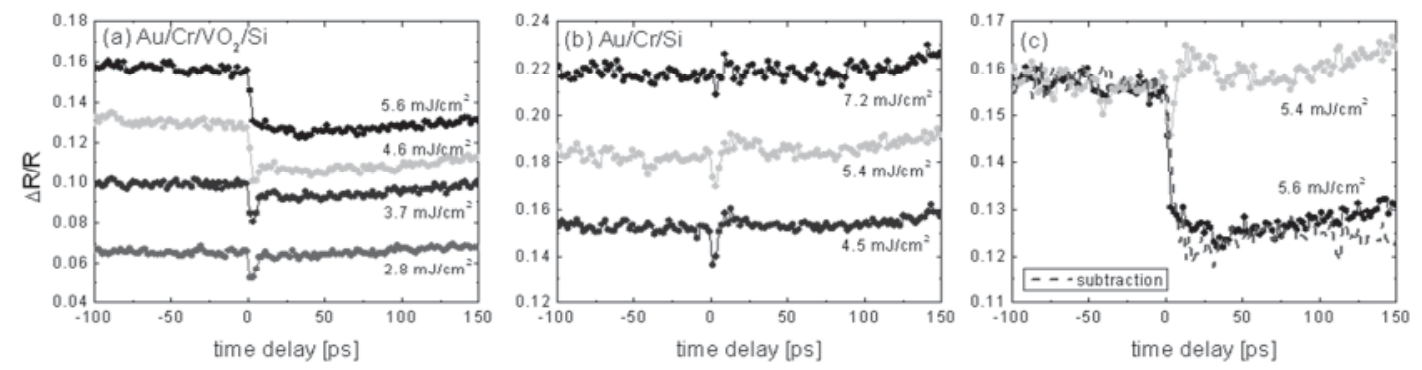

Fig. 1. Changes in reflectivity with delay time for $\mathrm{Au} / \mathrm{Cr} / \mathrm{VO}_{2} / \mathrm{Si}$ (a) and $\mathrm{Au} / \mathrm{Cr} / \mathrm{Si}$ (b) at the laserabsorbed fluence values of $2.8-7.2 \mathrm{~mJ} / \mathrm{cm}^{2}$, as indicated. In (c), the dush line represents the subtracted change in the reflectivity of $\mathrm{Au} / \mathrm{Cr} / \mathrm{Si}$ from that of $\mathrm{Au} / \mathrm{Cr} / \mathrm{VO}_{2} / \mathrm{Si}$ at the incident fluence of $5.6 \mathrm{~mJ} / \mathrm{cm}^{2}$.

Because of the top $\mathrm{Au}$ film, only $10 \%$ of the optical pulse could reach the $\mathrm{VO}_{2}$ surface, far below less the threshold fluence required for photo-induction of the SMT in $\mathrm{VO}_{2}$. Given the probepenetration depth of $\sim 30 \mathrm{~nm}$ and the thermal diffusion coefficient of $0.02 \mathrm{~cm}^{2} / \mathrm{s}$ [9], it would take more than $100 \mathrm{ps}$ to excite the probed area with thermal lattice diffusion. Because the sound speed in $\mathrm{VO}_{2}$ is $4 \times 10^{3} \mathrm{~m} / \mathrm{s}[10]$, acoustic relaxation into shear components will occur within around $10 \mathrm{ps}$ for a length scale of tens of nanometer. SMT observed in $\mathrm{VO}_{2}$ in this experiment occurred much faster than the rate of these thermal processes and the reflectivity change in the time scale of $\sim 2$ ps cannot be explained by either optical or thermal processes. The optical pulses produced a significant amount of hot electrons in the Au layer, which can induce the SMT in the underlying $\mathrm{VO}_{2}$. The contact between $\mathrm{Au} / \mathrm{Cr}$ and $\mathrm{VO}_{2}$ and the band-gap of $\mathrm{VO}_{2}$ in semiconductor phase makes ohmic junction$[11,12]$. The temperature of the hot electrons $\left(T_{e}\right)$ produced in the Au layer can be calculated with the laser absorbed fluence $(P)$ and heat capacity $\left(C_{e}\right)$ as:

$$
P=\int_{T_{0}}^{T_{e}} C_{e} t d t=\frac{1}{2} C_{e}\left(T_{e}^{2}-T_{0}^{2}\right)
$$


where $T_{0}$ is room temperature (293 K) (Ref. 13). The hot electrons generated on the Au surface would be transported ballistically through the $20 \mathrm{~nm}$-layer by the ballistic electron motion within $100 \mathrm{fs}$. According to equation (1), the temperature of the hot electrons at a laser fluence of $5 \mathrm{~mJ} / \mathrm{cm}^{2}$ would be $7000 \mathrm{~K}(0.6 \mathrm{eV})$. In case of the photo-induced phase transition, it is required $\sim 5 \%$ of excited electron from valence band to conduction band for the phase transition. From the FermiDirac distribution with the electron temperature of $7000 \mathrm{~K}$, the electron numbers of $\sim 5 \%$ corresponds to the electron energy of $1-2 \mathrm{eV}$. The penetration depth of the $1-2 \mathrm{eV}$ electrons in $\mathrm{VO}_{2}$ is around a few nanometers; therefore, the direct injection and primary scattering of electrons will transfer the energy to the cold $\mathrm{VO}_{2}$ lattice, which could trigger SMT.

\section{Conclusion}

This work illustrates that it is possible to exploit hot electrons to induce structural phase transitions and provides a new approach for stimulating structural transitions along ground state surface. This method could greatly extend the range of atomically resolved structural dynamics as well as provide a general means for inducing structural transitions in otherwise transparent materials.

\section{References}

1. F.J. Morin, Phys. Rev. Lett. 3, 34-36 (1959).

2. M.F. Becker, A.B. Buckman, R.M. Walser, Appl. Phys. Lett. 65, 1507-1509 (1994).

3. A. Cavalleri, M. Rini, R.W. Schoenlein, J. Phys. Soc. Jpn. 75, 011004 (2006).

4. A. Cavalleri, Cs. Tóth, C.W. Siders, J.A. Squier, F. Ráksi, P. Forget J.C. Kieffer, Phys. Rev. Lett. 87, 237401 (2001).

5. M. Hada, K. Okimura, J. Matsuo, Phys. Rev. B 82, 153401 (2010).

6. S. Biermann A. Poteryaev, A.I. Lichtenstein, A. Georges, Phys. Rev. Lett. 94, 026404 (2005).

7. D. W. Ferrara, E.R. MacQuarrie, J. Nag, A.B. Kaye, and R.F. Haglund, Jr., Appl. Phys. Lett. 98, $241112(2011)$.

8. S.D. Brorson, J.G. Fujimoto, E.P. Ippen, Phys. Rev. Lett. 59, 1962-1965 (1987).

9. C.N. Berglund, H.J. Guggenheim, Phys. Rev. 185, 1022 (1969).

10. D. Maurer, A. Leue, R. Heichele, V. Muller, Phys. Rev. B 60, 13249 (1999).

11. Y. Wang, Z. Zhang, Physica E 41, 548 (2009).

12. G. Xu, C.-M. Huang, M. Tazawa, P. Jin, D.-M. Chen, L. Miao, Appl. Phys. Lett. 93, 061911 (2008).

13. Z. Lin, L.V. Zhigilei, V. Celli, Phys. Rev. B 77, 075133 (2008). 